\title{
A pathophysiological role of PDE3 in allergic airway inflammation
}

\author{
Jan Beute, ${ }^{1}$ Melanie Lukkes, ${ }^{1}$ Ewout P. Koekoek, ${ }^{1}$ Hedwika Nastiti, ${ }^{1}$ Keerthana Ganesh, ${ }^{1}$ \\ Marjolein J.W. de Bruijn, ${ }^{1}$ Steve Hockman, ${ }^{2}$ Menno van Nimwegen, ${ }^{1}$ Gert-Jan Braunstahl, ${ }^{3}$ \\ Louis Boon, ${ }^{4}$ Bart N. Lambrecht, ${ }^{1,5}$ Vince C. Manganiello, ${ }^{2}$ Rudi W. Hendriks, ${ }^{1}$ and Alex KleinJan ${ }^{1}$ \\ 'Department of Pulmonary Medicine, Erasmus MC, 's-Gravendijkwal, Rotterdam, Netherlands. ${ }^{2}$ Cardiovascular \\ and Pulmonary Branch, National Heart, Lung, and Blood Institute, NIH, Bethesda, Maryland USA. ${ }^{3}$ Department of \\ Pulmonology, Franciscus Gasthuis, Rotterdam, Netherlands. 'Epirus Biopharmaceuticals Netherlands Yalelaan, Utrecht, \\ Netherlands. ${ }^{5}$ VIB Center for Inflammation Research, Ghent University, Ghent, Belgium.
}

Phosphodiesterase 3 (PDE3) and PDE4 regulate levels of cyclic AMP, which are critical in various cell types involved in allergic airway inflammation. Although PDE4 inhibition attenuates allergic airway inflammation, reported side effects preclude its application as an antiasthma drug in humans. Case reports showed that enoximone, which is a smooth muscle relaxant that inhibits PDE3, is beneficial and lifesaving in status asthmaticus and is well tolerated. However, clinical observations also showed antiinflammatory effects of PDE3 inhibition. In this study, we investigated the role of PDE3 in a house dust mite-driven (HDM-driven) allergic airway inflammation (AAI) model that is characterized by $\mathrm{T}$ helper 2 cell activation, eosinophilia, and reduced mucosal barrier function. Compared with wild-type (WT) littermates, mice with a targeted deletion of the PDE3A or PDE3B gene showed significantly reduced HDM-driven AAI. Therapeutic intervention in WT mice showed that all hallmarks of HDM-driven AAI were abrogated by the PDE3 inhibitors enoximone and milrinone. Importantly, we found that enoximone also reduced the upregulation of the CD11b integrin on mouse and human eosinophils in vitro, which is crucial for their recruitment during allergic inflammation. This study provides evidence for a hitherto unknown antiinflammatory role of PDE3 inhibition in allergic airway inflammation and offers a potentially novel treatment approach.

Authorship note: V.C. Manganiello is deceased.

Conflict of interest: J. Beute is inventor on a pending patent application (PCT/ NL2015/050246).

Submitted: May 16, 2017

Accepted: December 12, 2017

Published: January 25, 2018

\section{Reference information:}

JCI Insight. 2018;3(2):e94888.

https://doi.org/10.1172/jci.

insight. 94888.

\section{Introduction}

Asthma is an obstructive airway disease characterized by inflamed airways, structural and physiological abnormalities of the airways, and shortness of breath (1). Although impressive progress has been made in the treatment of asthma, there still is a significantly high number of uncontrolled severe asthma (2) and asthma deaths worldwide, and consequently a great need for lifesaving therapy (3).

There are 11 isoenzyme families of phosphodiesterases (PDEs). In the context of allergic airway inflammation and asthma, PDE3 and PDE4 are most relevant and widely expressed in airway cells including epithelial cells, endothelial cells, smooth muscle cells, and inflammatory cells (4-9). PDE3 has 2 isoforms (PDE3A and PDE3B) and is a cAMP- and cGMP-specific PDE; PDE4 has 4 isoforms (PDE4A, -B, $-\mathrm{C}$, and -D) and is cAMP specific. PDE4 inhibitors appear to act effectively on immune cells, as well as on endothelial cells, epithelial cells, and airway smooth muscle cells (10). The lack or inhibition of PDE4, an asthma susceptibility gene (11), attenuates airway hyperresponsiveness and airway inflammation in mouse models of allergic airway inflammation (12-18). It is known that genetic variants of PDE4D are associated with asthma (19) and PDE3 inhibition induces smooth muscle cell relaxation with the consequence of bronchodilation (20). Recently, research has focused on the synergy of preparations that combine PDE3and PDE4-inhibiting effects (21).

Increasing cAMP levels reduces the expression of adhesion molecules and consequently impairs eosinophil and neutrophil adherence to human lung endothelial cells (6). PDE4 isoforms are expressed by both immune cells and structural tissue cells (22), but also in the brain (23), which makes broad-spectrum PDE4 inhibitors like roflumilast less promising as antiasthma drugs in humans (24). When PDE4 inhibitors are dosed according to their advisory dose they may show frequently mild to severe side 
effects including diarrhea, headache, and nausea. Even suicides have been reported (25). Presently, no specific PDE4 inhibitor is available for asthma.

Some promising results have been reported for the dual PDE3/4 inhibitor RPL554, which is already in a phase II clinical trial for asthma (21). Although RPL554 is described as a dual inhibitor, it is 3,750-fold more potent for PDE3 compared with PDE4. It has a half-life $\left(\mathrm{t}^{1} \frac{1}{2}\right)$ of 11 hours $(21,24)$ and was shown to be effective in an asthma model (7). PDE4 and combined PDE3/4 inhibition may enhance the effects of glucocorticoid treatment $(26,27)$. Since the major action of RPL554 is PDE3 inhibition, it is important to know what the exact contribution of PDE3 is to allergic airway inflammation. Several lines of evidence support a critical role for PDE3 in cell-cell interactions, including endothelial barrier function and cell junctions (28-31). The data available from PDE3 inhibitors during the 1990s concerned only drugs with a short $\mathrm{t}^{1 / 2}$ and failed to show beneficial effects in asthma models, involving long incubation times. At the moment, RPL554 is the only drug available in experimental settings and has not been tested in patients with severe disease. We recently demonstrated beneficial and life-saving effects of the PDE3 inhibitor enoximone in status asthmaticus (32), which were based on enoximone's known bronchodilatory capacity (20). PDE3 inhibition literature of the 1990s did not show any antiinflammatory effects in animal models of allergic inflammation (33-36). We suggest that this absence of proof may be due to inadequate dosing, a wrong model, and limited use of PDE3 inhibitors. However, clinical data suggest that PDE3 inhibition therapy given via infusion in heart failure, bypass operations, and enterovirus 71 infection did show antiinflammatory effects (37-39). During the last decade, a growing number of studies suggest that PDE3 inhibition might be involved in immunosuppression (40-48), although there is no definitive proof. There have been concerns that PDE3 inhibitors were associated with increased cardiovascular mortality in previous clinical trials (49, 50). However, a better picture is given by the ESSENTIAL clinical trial (51), where the outcome of the study was that $150 \mathrm{mg}$ oral enoximone per day compared with placebo neither improved advanced heart failure (HF) nor aggravated it, and did not show adverse effects even in heart failure patients.

Based on clinical observations, we wanted to investigate whether PDE3 inhibition might induce an antiallergic effect. We investigated the role of PDE3 in an acute house dust mite-driven (HDM-driven) allergic airway inflammation mouse model. We studied the phenotype of PDE3A and PDE3B single-deficient mice. Moreover, we demonstrated the effect of PDE3 inhibition in vivo. Both PDE3 deficiency and pharmacological inhibition of PDE3 activity reduced allergic airway inflammation and improved endothelial barrier function in this asthma model.

\section{Results}

High expression of PDE3 and PDE4 in lung mucosal tissue obtained from healthy controls and asthmatic patients. To begin with, we studied protein and mRNA expression of PDE3 and PDE4 isoforms in the airways and immune cells. PDE3A and PDE3B proteins were detected in the epithelium, endothelium, smooth muscle cells, and inflammatory cells. No differences in PDE3 protein (Supplemental Figure 1, A and B; supplemental material available online with this article; https://doi.org/10.1172/jci.insight.94888DS1) or mRNA expression (Supplemental Figure 1C) were seen in human lung mucosal biopsies with eosinophilic airway inflammation (Supplemental Figure 1D) or murine lung mucosal samples using quantitative PCR (qPCR) (Supplemental Figure 2A). Cultured murine B cells and dendritic cells (DCs) expressed PDE3B (Supplemental Figure 2, B and C). IgM activation of B cells induced increased expression of PDE3B in B cells. HDM activation of DCs reduced PDE3B expression. Naive and CD4 ${ }^{+} \mathrm{T}$ cells differentiated into various $\mathrm{Th}$ subsets, expressing high levels of PDE3B, PDE4A, PDE4B, and PDE4D (Supplemental Figure 2D).

We found that although structural lung cells expressed both PDE3A and PDE3B, inflammatory cells expressed mainly the PDE3B isoform and PDE4.

Absence of PDE3A or PDE3B expression results in a reduced inflammatory response in an HDM-driven allergic airway inflammation model in mice. Since PDE3 is widely expressed in lung cells, including inflammatory cells, we examined the specific role of PDE3 in allergic airway inflammation. We investigated eosinophilic airway inflammation in 3 subsets of mice: $P D E 3 A^{-/-}$mice, $P D E 3 B^{-/-}$mice, and WT littermates. We used an HDM-driven model for allergic airway inflammation according to the schedule depicted in Figure $1 \mathrm{~A}$. HDM-treated WT mice demonstrated a clear eosinophilic airway inflammation (Figure 1B). The numbers of eosinophils in bronchoalveolar lavage (BAL) fluid were significantly higher in HDM-treated WT mice when compared with PBS-treated control mice (Figure 1C). The eosinophil number was 6-fold higher in WT 
A

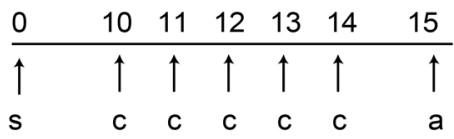

B
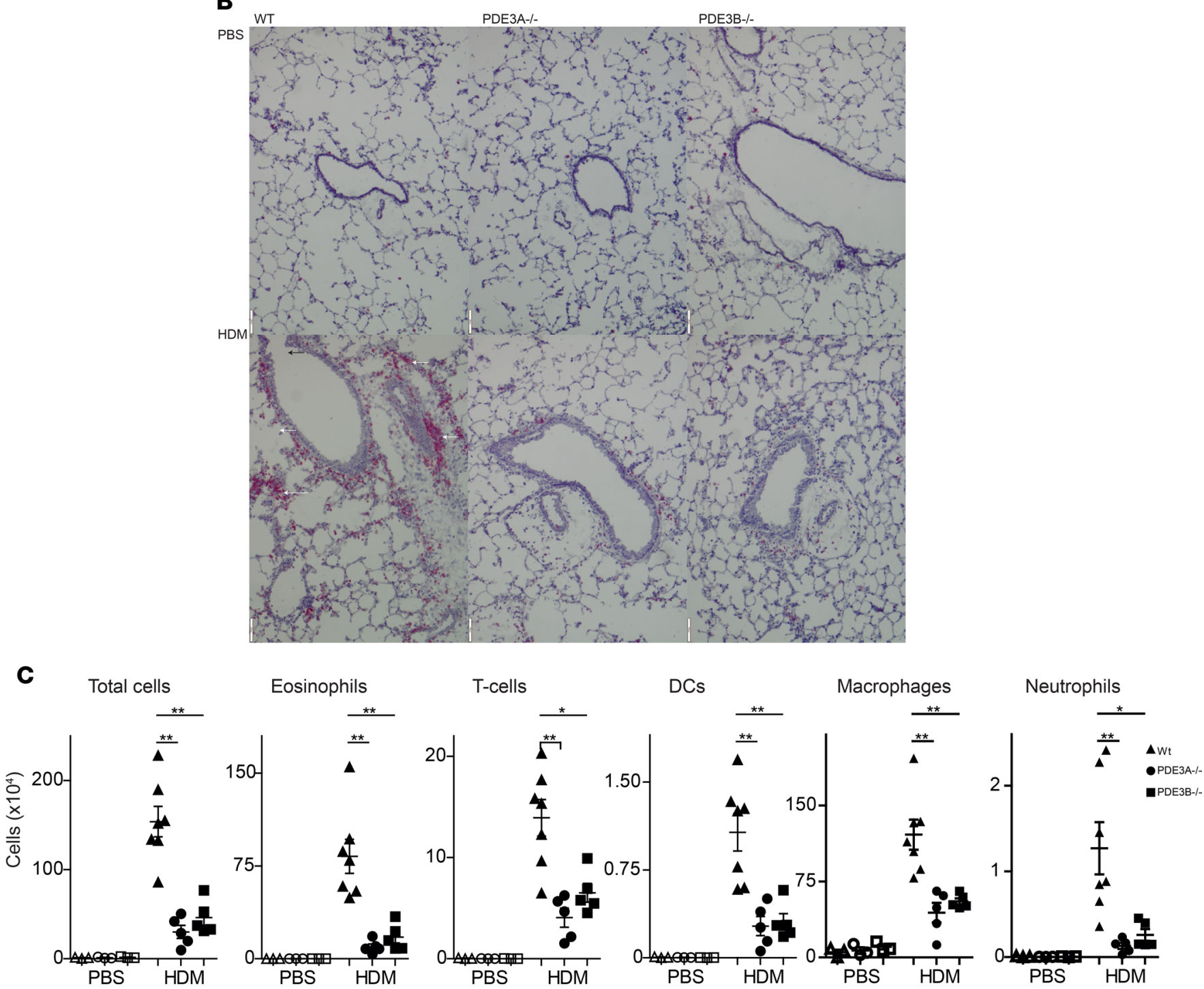

Figure 1. PDE3 ${ }^{-/-}$mice showed diminished allergic airway inflammation. (A) An experimental house dust mite (HDM) asthma model was designed using intratracheal sensitization (s) and challenge (c) of $10 \mu \mathrm{g}$ HDM or PBS as control. Analyses (a) were performed 1 day after the last challenge. Days after sensitization are indicated at the top. (B) Frozen lung sections were obtained from WT, PDE3A $A^{-1-}$, and $P D E 3 B^{-/-}$mice treated with PBS or HDM and immunohistochemically stained with rat antibodies against Siglec $F(r e d)$ to identify eosinophils. The nuclei stained blue by means of Gills hematoxylin. All images are centered on at least one bronchiole with an accompanying blood vessel, surrounded by parenchymal alveolar space. Strongly positive dark red cells with a donut- or lobe-shaped nucleus were identified as eosinophils, whereas the larger, fainter red cells with a membrane staining were identified as alveolar macrophages. Original magnification, $\times 100$. Scale bars: $100 \mu \mathrm{m}$. (C) FACS analysis and quantification of bronchoalveolar lavage (BAL) cells (total cells, eosinophils, T cells, DCs, macrophages, and neutrophils) were plotted in indicated populations. Kruskal-Wallis test for multiple comparisons was used followed by Mann-Whitney $U$ test. Data represent 2 separate experiments ( $n=3$ for all PBS groups, $n=7$ for WT HDM, $n=5$ for both PDE3A ${ }^{-/-}$ and $P D E 3 B^{-/-}$HDM groups) and are shown as the mean \pm SEM. ${ }^{*} P<0.05,{ }^{* *} P<0.01$.

mice when compared with $P D E 3 A^{-/-}$mice and 5-fold higher when compared with the $P D E 3 B^{-/}$mice (Figure 1C). Other inflammatory cell counts, including T cells, neutrophils, macrophages, and DCs, followed roughly the same pattern (Figure 1C and Supplemental Figure 2). T cells showed an approximately 3-fold higher number in HDM-treated WT mice when compared with HDM-treated $P D E 3 A^{-/-}$or $P D E 3 B^{-1-}$ mice. 
All findings supported the hypothesis that the absence of either PDE3A or PDE3B activity attenuates eosinophilic airway inflammation in an HDM-driven allergic airway inflammation model in mice.

$P D E 3 A^{-1-}$ and $P D E 3 B^{-1-}$ mice show a reduced Th2 cytokine response and a decreased level of the proinflammatory cytokine TNF- $\alpha$. The presence of eosinophils is indirect proof that a Th2 lymphocyte response to $\mathrm{HDM}$ was induced. Because the cellular inflammatory reaction was strongly reduced in $P D E 3 A^{-/-}$mice and $P D E 3 B^{-1-}$ mice, we investigated whether this reaction was mitigated due to an impaired Th2 response. Indeed, both proportions and cell numbers of IL-5- and IL-13-positive CD4 ${ }^{+} \mathrm{T}$ cells in BAL were reduced in HDM-treated $P D E 3 A^{-/-}$and $P D E 3 B^{-/-}$mice when compared with HDM-treated WT mice (Figure 2, A and $\mathrm{B}$ ). As we had been able to demonstrate that both generalized inflammation and Th2-cell cytokine production were less in both types of $P D E 3^{-/}$mice, we also investigated the cytokines produced in the alveolar lumen by BAL fluid analysis. We found lower levels of the proinflammatory cytokine TNF- $\alpha$ and the Th2 cytokine IL-5 in $P D E 3 A^{-/-}$and $P D E 3 A^{-/-}$mice when compared with WT mice in our model (Figure 2C). We were not able to demonstrate different keratinocyte-derived protein chemokine (KC) (murine IL-8) levels in HDM-treated WT, $P D E 3 A^{-/-}$, and $P D E 3 B^{-/-}$mice, compared with PBS-treated mice. Cytokine production is an important feature in allergies, so we next investigated cytokine production in in vitro HDM-restimulated, lung draining mediastinal lymph node (MLN) cells by ELISA. In WT mice MLN cultures, we observed a marked increase of IL-4, IL-5, and IL-13 (Figure 2D), indicating HDM-specific reactivity of MLN cells, most probably $\mathrm{CD}^{+} \mathrm{T}$ cells (Figure $2 \mathrm{~A}$ ). In contrast, MLN cultures from $P D E 3 A^{-1}$ and $P D E 3 B^{-1-}$ mice showed markedly reduced Th2 cytokine production. On the other hand, IFN- $\gamma$ was induced in all MLN cultures from WT, $P D E 3 A^{-/-}$and $P D E 3 B^{-/-}$mice at similar levels.

We concluded that HDM-reactive T helper cells in mice lacking PDE3 produce less Th2 cytokine, while IFN- $\gamma$ is unaffected. Moreover, the proinflammatory cytokine TNF- $\alpha$, as measured in BAL fluid, is lower in $P D E 3^{--}$mice, illustrating less pronounced immune activation when compared with WT mice in allergic airway inflammation.

$P D E 3 A^{-1-}$ and $P D E 3 B^{-1-}$ mice show reduced albumin leakage in an HDM-driven allergic airway inflammation model. Endothelial cells are an important target of TNF- $\alpha$, since its proinflammatory effects lead to increased permeability across endothelial cells. The next step in this study was to demonstrate this endothelial permeability by analysis of the leakage of large serum proteins like albumin $(52,53)$. When endothelial barrier function is impaired, more albumin will leak through the airway's endothelium into the lung mucosal tissue (edema), which in turn is responsible for additional airway narrowing in asthmatics (54). The PDE3 inhibitor cilostazol has been shown to improve barrier function by reducing leakage of albumin in vitro (55). We studied albumin leakage in both lung tissue and alveolar lumen by ELISA, which is reliable, instead of indirect Evans blue dye techniques $(52,53,56)$. Initially, PBS-treated WT, $P D E 3 A^{-/-}$, and $P D E 3 B^{-/-}$mice had albumin levels that are within the normal range. This implies that barrier function is unaffected under noninflammatory conditions. When challenged with HDM, WT mice displayed an increase in albumin content, suggesting greater leakage, which was not observed in the $P D E 3 A^{-/-}$or $P D E 3 B^{-1-}$ mice (Figure $3 \mathrm{~A}$ ).

During inflammation, the vasculature leaks proteins because of the large interendothelial cell spaces as stated above, this leakage causes edema, which in turn causes additional airway narrowing in asthmatics. To investigate this, lung tissue sections were stained and analyzed for their albumin content (for details see the Methods; for quantification see Figure 3, B and C and representative examples D-L). Albumin intensity was centered primarily on the airway vasculature in PBS-treated mice. Additionally, some albumin staining was seen in bronchial mucus in HDM-treated mice, indicating that during inflammation tissue albumin progresses into the mucus as well. However, most of the direct leakage from the larger blood vessels was observed in the perivascular region (especially clear in the images of Figure 3, D-F). When comparing HDM-treated WT mice (Figure 3, G and $\mathrm{J}$ ) with $P D E 3 A^{-1-}$ and $P D E 3 B^{-1-}$ mice (Figure 3, $\mathrm{H}$, $\mathrm{I}, \mathrm{K}$, and $\mathrm{L}$ ), the peribronchial region directly surrounding the bronchioles appeared less albumin-infused in the $P D E 3 A^{-1-}$ and $P D E 3 B^{-1-}$ HDM-treated mice. When looking more closely at the peribronchial region (selections highlighted in white in Figure 3, J-L) it becomes apparent that in WT mice (Figure 3J) the small vasculature surrounding the bronchioli (highlighted with white arrows) was much more intensely stained for albumin when compared with the $P D E 3 A^{-/-}$and $P D E 3 B^{-/-}$mice (Figure 3, $\mathrm{K}$ and L). Compared with WT mice, HDM-treated $P D E 3 A^{-/-}$mice displayed a significantly reduced increase of albumin content in both peribronchial and perivascular leakage, whereas HDM-treated $P D E 3 B^{-1-}$ mice only significantly differed from the WT HDM-treated animals in terms of peribronchial leakage. No marked differences were observed between the groups of PBS-treated mice, indicating that no albumin leakage occurred. 
A

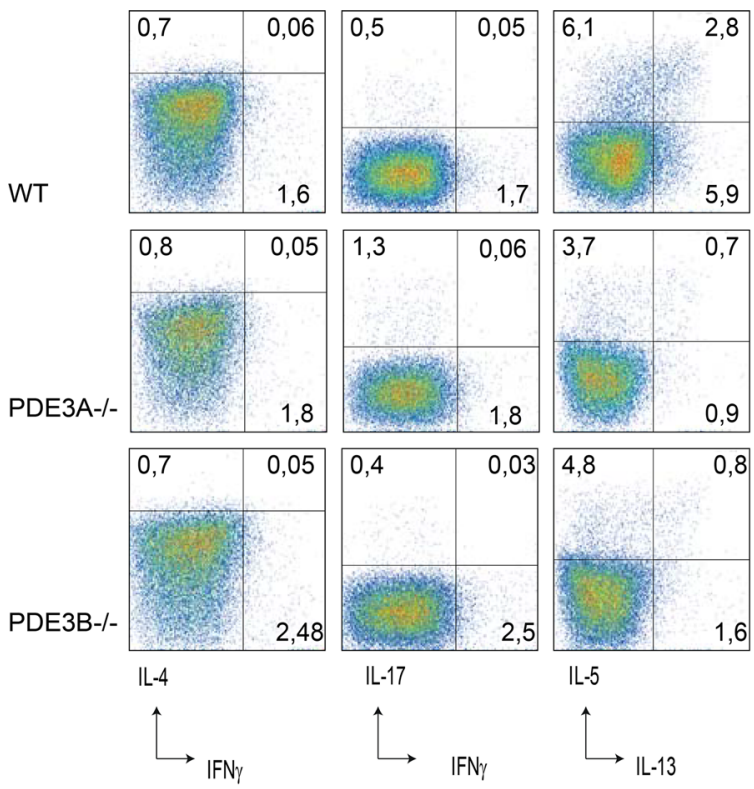

B IL-5+CD4+ cells IL-13+CD4+ cells IL-4+CD4+ cells IF Ng+CD4+ cells IL-17+CD4+ cells

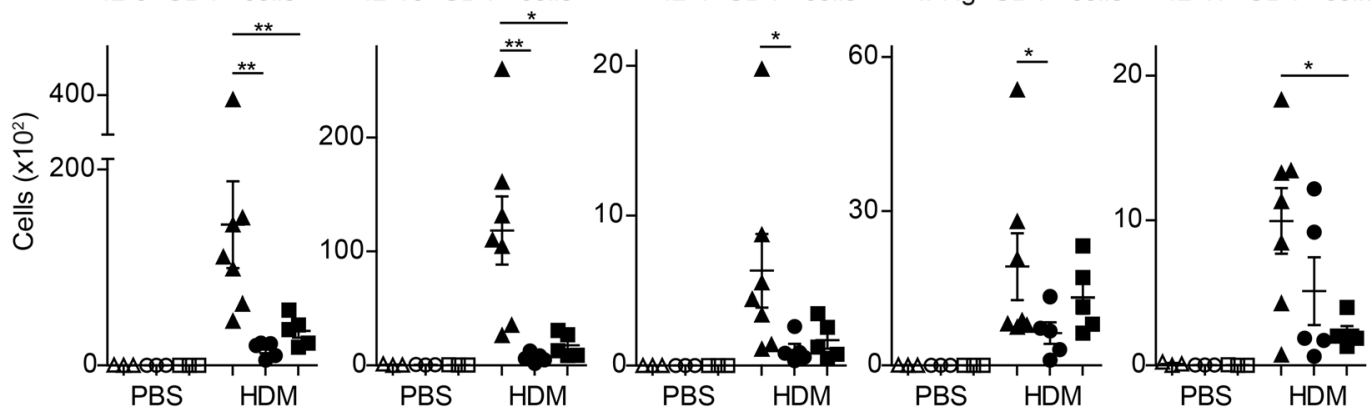

C

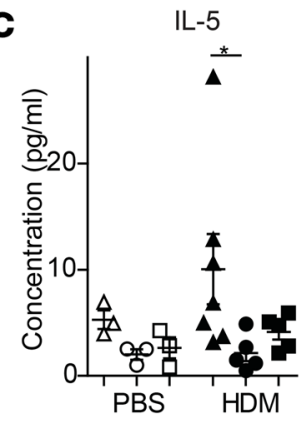

KC
TNF $\alpha$

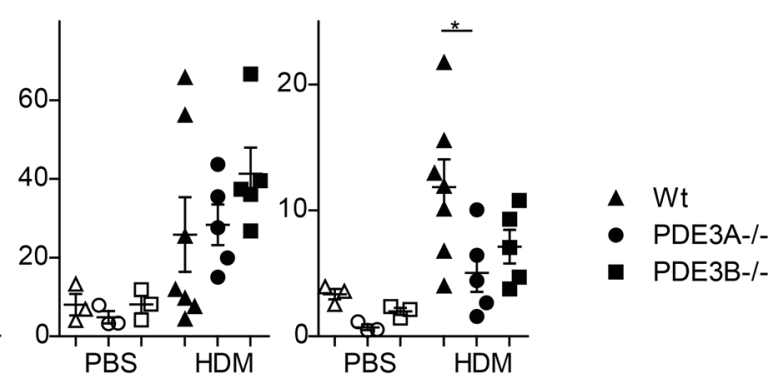

D

IL-4

IL-5 *

IL-13

$\stackrel{* *}{*}$
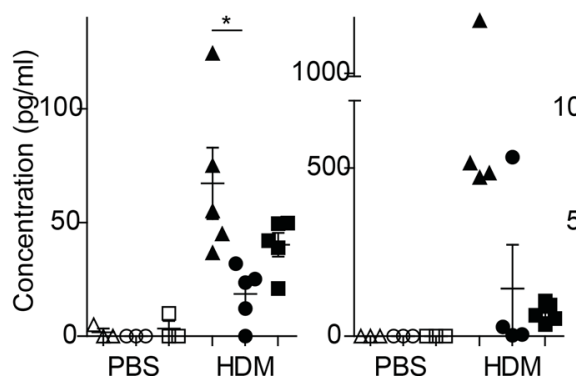

$\mathrm{IFN \gamma}$

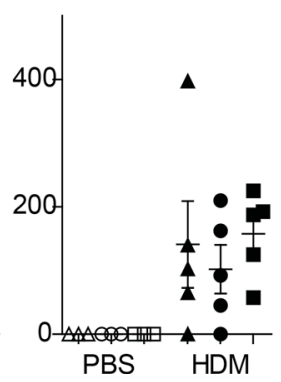

Figure 2. $P D E 3^{-/-}$mice showed diminished Th2 cytokine in HDM-restimulated MLN cell suspension and BAL fluids. (A) Intracellular cytokine expression profiles (proportion and numbers) of gated bronchoalveolar lavage (BAL) $\mathrm{CD}^{+} \mathrm{CD}^{+} \mathrm{T}$ cells upon 4 hours of PMA/ionomycin stimulation. (B) Quantification of flow cytometric analyses of the indicated populations of BAL $\mathrm{CD3}^{+} \mathrm{CD} 4$ T cells. (C) BAL fluids were assayed with ELISA for indicated cytokines. (D) Single-cell suspensions of mediastinal lymph node (MLN) cells were restimulated with $1 \mu \mathrm{g} / \mathrm{ml}$ house dust mite (HDM) for 7 days and supernatants were assayed with ELISA for indicated cytokines. Kruskal-Wallis test for multiple comparisons was used followed by Mann-Whitney $U$ test. Data represent 2 separate experiments ( $n=3$ for all PBS groups, $n=7$ for WT HDM, $n=5$ for both PDE3 $A^{-/-}$and $P D E 3 B^{-/-}$HDM groups) and are shown as the mean \pm SEM. ${ }^{*} P<0.05,{ }^{* *} P<0.01$. 


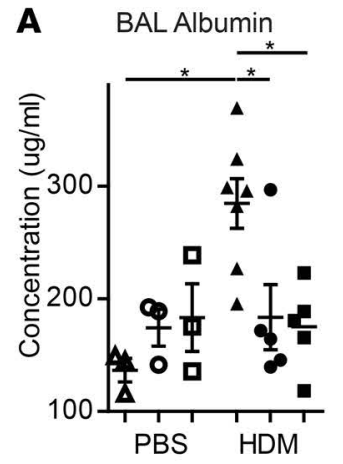

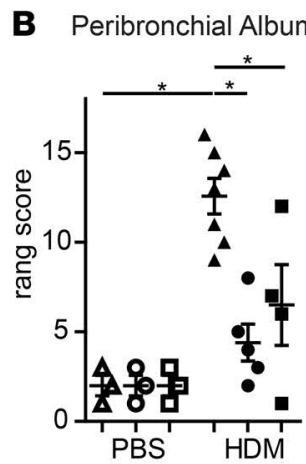

C

Perivascular Albumin

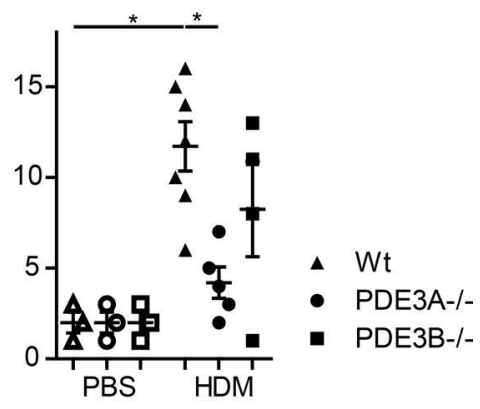

WT
PDE3A -/-

\section{PDE3B -/-}

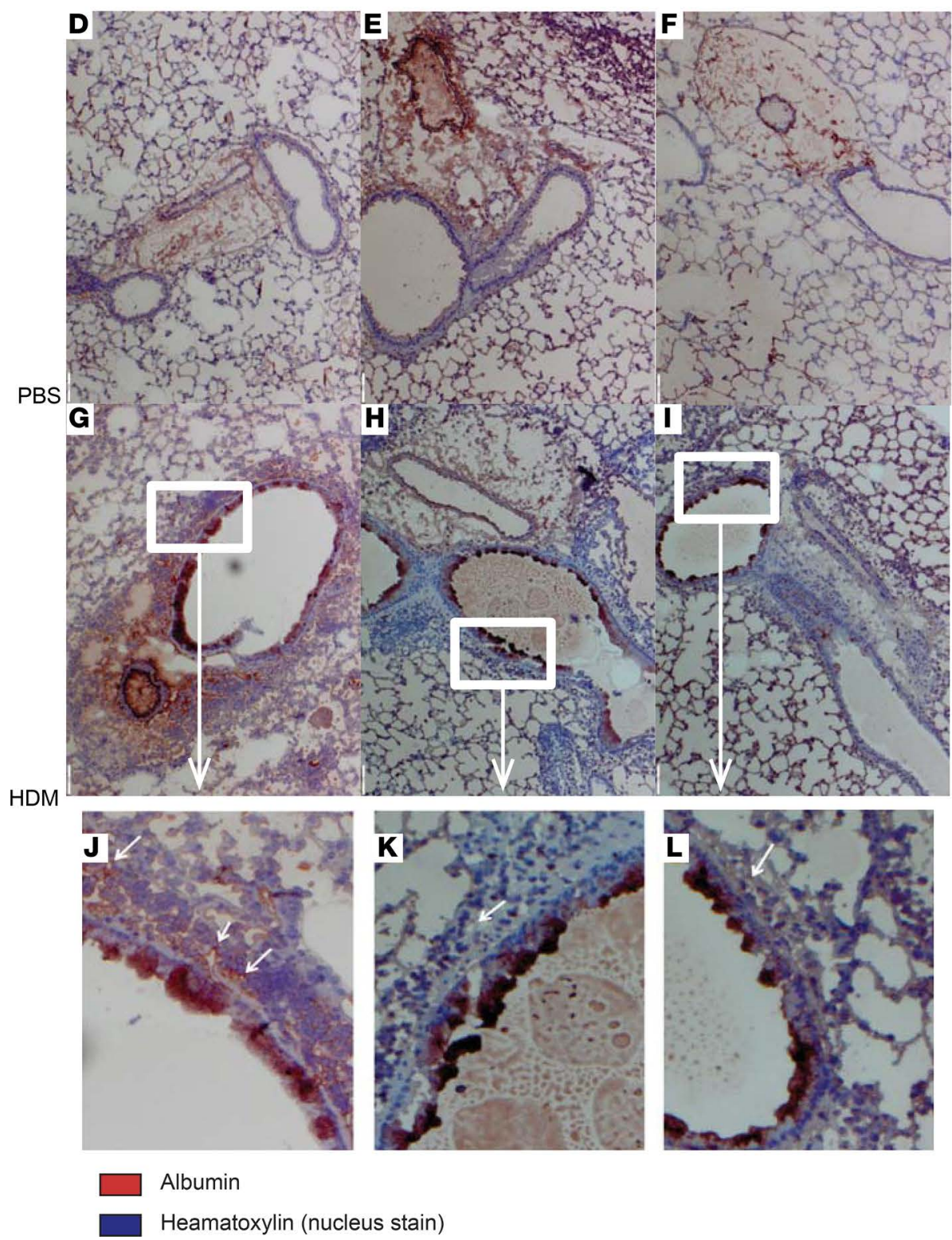

Figure 3. Less albumin extravasation in HDM-treated PDE3 $^{-/-}$mice compared with WT mice. (A) Albumin content in bronchoalveolar lavage (BAL) fluids of WT versus $P D E 3^{-/-}$mice was assayed with ELISA. Ranking score results of the peribronchial (B) and perivascular (C) albumin leakage judged from the lung tissue sections of WT and $P D E 3^{-/-}$mice. Frozen tissue sections of WT and $P D E 3^{-/-}$mice were stained for albumin (brown-red) and counterstained with Gills hematoxylin (blue) at $\times 5(\mathbf{D}-\mathbf{I})$ and $\times 20$ magnification (J-L). Albumin positivity can be seen throughout the entirety of the lung tissue, but is mainly sequestered inside the large blood vessels, perivascular as well as peribronchial. Mucus was also stained for albumin. PBS-treated mice (A-C) were indistinguishable from each other concerning albumin content. WT HDM-treated mice (G and J) showed albumin positivity surrounding the bronchioles when compared with $P D E 3^{-/-}$mice $(\mathbf{H}$, $\mathbf{I}, \mathbf{K}$, and $\mathbf{L})$. Original magnification, $\times 100$. Zooming in on $(\times 400)$ the peribronchial region (highlighted with white rectangle), the smaller vasculature surrounding the bronchiole is albumin-positive in WT mice (J) (highlighted with white arrows) when compared with the $P D E 3^{-1-}$ mice (K and $\mathbf{L}$ ). Kruskal-Wallis test for multiple comparisons was used followed by Mann-Whitney $U$ test. Data represent 2 separate experiments ( $n=3$ for all PBS groups, $n=$ 7 for WT HDM, $n=5$ for both PDE3A $A^{-/-}$and $P D E 3 B^{-1-}$ HDM groups) and are shown as the mean \pm SEM. ${ }^{*} P<0.05$.

In summary, the findings in these tests demonstrate that $P D E 3^{--}$mice had less vascular albumin leakage, indicating an improved barrier function under inflammatory conditions when compared with WT mice.

PDE3 inhibition attenuates allergic airway inflammation. Because lack of PDE3 activity improved the cardinal pathophysiological manifestations of asthma including airway inflammation and edema formation, we 
A

\begin{tabular}{ccccccc}
0 & 10 & 11 & 12 & 13 & 14 & 15 \\
\hline$\uparrow$ & $\uparrow$ & $\uparrow$ & $\uparrow$ & $\uparrow$ & $\uparrow$ & $\uparrow$ \\
$\mathrm{s}$ & $\mathrm{c}$ & $\mathrm{c}$ & $\mathrm{c}$ & $\mathrm{c}$ & $\mathrm{c}$ & $\mathrm{a}$ \\
& $\mathrm{e}$ & $\mathrm{e}$ & $\mathrm{e}$ & $\mathrm{e}$ & $\mathrm{e}$ &
\end{tabular}
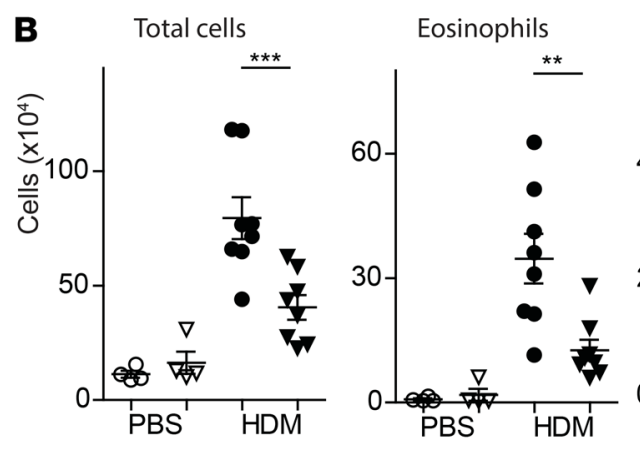

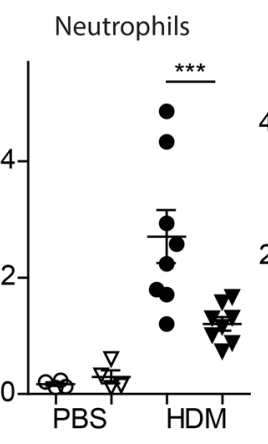

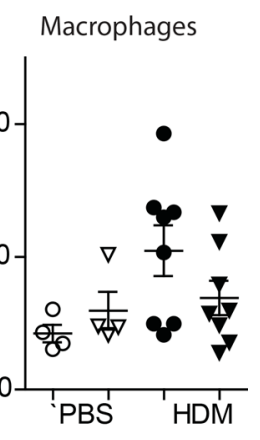

Figure 4. Topical enoximone abrogated HDM-induced allergic airway inflammation. (A) Experimental house dust mite (HDM) asthma design showing intratracheal sensitization (s) and challenge (c) of $10 \mu \mathrm{g}$ HDM admixed with diluent or $25 \mu \mathrm{g}$ enoximone or PBS admixed with diluent or $25 \mu$ g enoximone as controls. Analyses (a) were performed 1 day after the last challenge. Days after sensitization are indicated at the top. Quantification of flow cytometric analyses of the indicated populations of bronchoalveolar lavage (BAL) cells (B), $T$ cells and dendritic cells (C), and mast cells and basophils (D). Mann-Whitney $U$ test was used. Data represent 2 separate experiments ( $n=4$ for all PBS groups, $n=8$ for HDM groups) and are shown as the mean \pm SEM. ${ }^{*} P<0.05$,

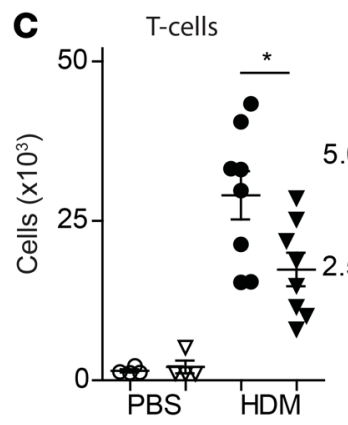

CD11b cDCs

CD103 DCs
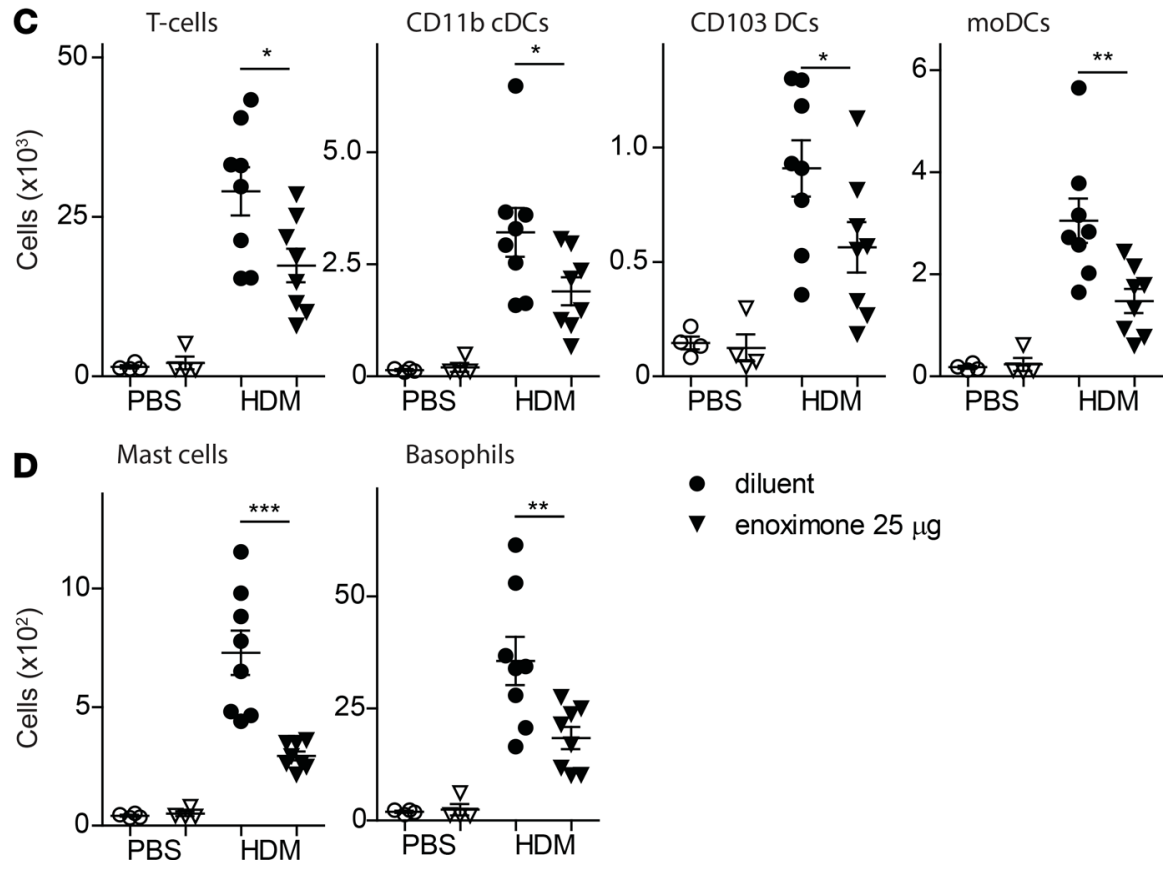

Basophils

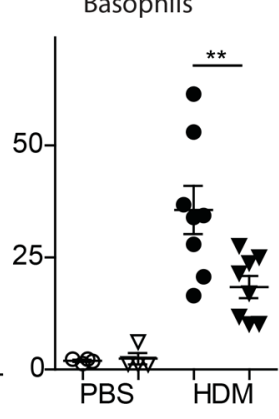

- diluent

$\boldsymbol{\nabla}$ enoximone $25 \mu \mathrm{g}$ ${ }^{* *} P<0.01,{ }^{* *} P<0.001$.

proceeded by targeting PDE3 in a therapeutic intervention using a PDE3 inhibitor. Successful off-label use of the PDE3 inhibitor enoximone was described in the context of status asthmaticus (32). Next to its PDE3 inhibitory properties (IC50 $=5.9 \mu \mathrm{M}$ ), enoximone also exhibits some PDE4 inhibitory effect, more specifically a myocardial PDE4A inhibitory effect $(\mathrm{IC} 50=21.1 \mu \mathrm{M})(57,58)$. Cardiomyocytes express mainly PDE4A1A (59). We used an HDM-driven mouse model for allergic airway inflammation according to the schedule depicted in Figure $4 \mathrm{~A}$, with enoximone or diluent given via the intratracheal route. A significant reduction of airway inflammation was seen in mice treated with optimal doses of enoximone (Figure 4, B-D and Supplemental Figure 4).

From these experiments, we concluded that targeting PDE3 - particularly during allergen challenge - prevents HDM-driven airway inflammation. Similar results were seen when enoximone was given via the oral route (Supplemental Figure 3).

Treatment with a PDE3 inhibitor reduces eosinophilia during ongoing allergic inflammation. We next investigated if PDE3 inhibition with enoximone is capable of attenuating airway inflammation in already established allergic airway inflammation. Prospectively, we created 3 different groups of WT mice (Figure 5A). One group consisted of PBS/diluent controls only. Two other groups were sensitized with HDM, followed by 5 additional HDM challenges on days 10-14 thereafter. Mice with allergic airway inflammation were then challenged again on 5 successive days (days 15-19) with HDM admixed (given simultaneously) with diluent 
A

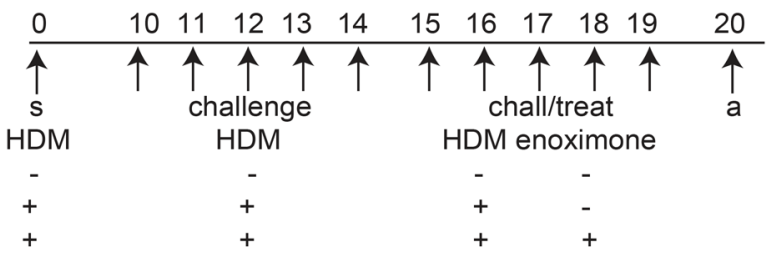

B

Total cells

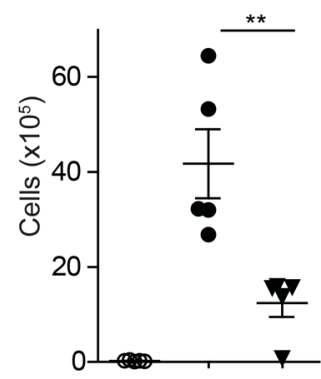

Eosinophils

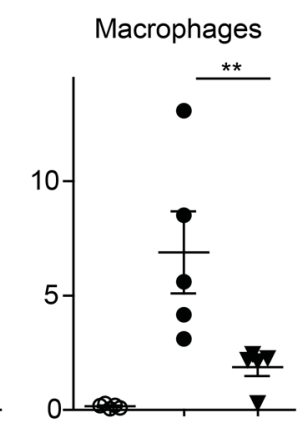

- PBS PBS diluent

- HDM HDM diluent

v HDM HDM enoximone

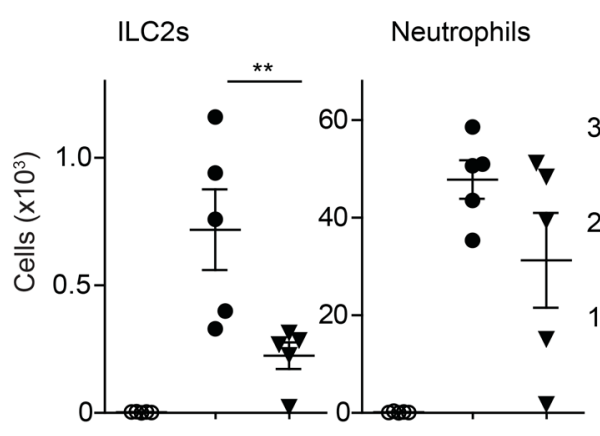

T-cells

DCs

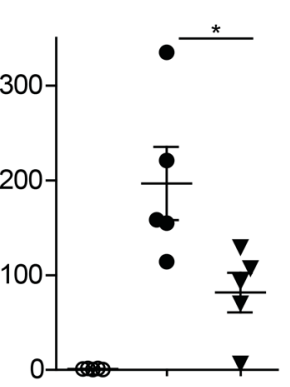

Figure 5. Topical (intratracheal) treatment with $25 \mu \mathrm{g}$ enoximone reduced allergic airway inflammation in established asthma in an HDM asthma model. (A) Experimental house dust mite (HDM) asthma model using intratracheal sensitization (s) of $1 \mu \mathrm{g} \mathrm{HDM}$ or PBS as control and intranasal challenge with $5 \mu \mathrm{g}$ HDM followed by challenge and treatment (chall/ treat). Days after sensitization are indicated at the top. (B) Quantification of flow cytometric analyses of bronchoalveolar lavage (BAL) cells of the indicated populations. (C) Quantification of cytokines of BAL CD4 ${ }^{+} T$ cells from flow cytometric analyses were plotted for indicated populations of BAL cells. Kruskal-Wallis test for multiple comparisons was used, followed by Mann-Whitney $U$ test. Data ( $n=4-5$ animals per group) are expressed as the mean \pm SEM. ${ }^{*} P<0.05,{ }^{* *} P<0.01$.

\section{C $\mathrm{IL}-4+\mathrm{CD} 4+$}

IL-5+ CD4+

IL-13+ CD4+

IL-17+ CD4+

IFNy + CD4+
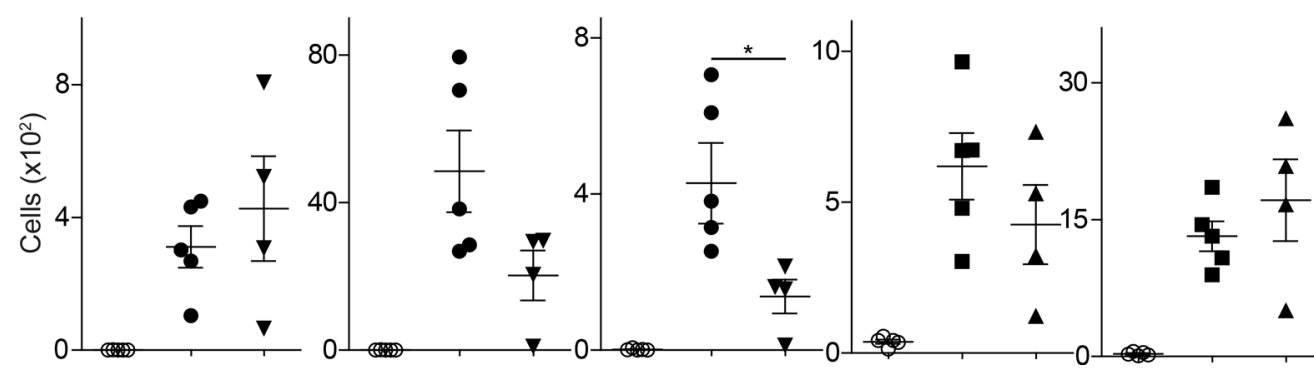

or enoximone (Figure 5A). At day 20, the controls showed no signs of allergic inflammation in the BAL. The diluent-treated HDM-exposed mice showed significantly increased levels of eosinophils, macrophages, group 2 innate lymphoid cells (ILC2s), and T cells, indicating an allergic reaction (Figure 5B). The enoximone-treated HDM-exposed mice showed significant reductions in inflammatory cell numbers including eosinophils, macrophages, ILC2s, and T cells, indicating that enoximone treatment reduced airway inflammation (Figure 5B). Induction of neutrophils was limited, but their numbers also tended to be lower in enoximone-treated mice compared with diluent-treated mice. We also investigated the numbers of Th2 cytokine-producing T cells and observed a significant reduction in IL-13-positive CD4 ${ }^{+} \mathrm{T}$ cells and IL-5-positive $\mathrm{CD}^{+} \mathrm{T}$ cells tended to be lower, while IFN- $\gamma$ - and IL-17-producing T cells remained the same (Figure 5C).

These data showed that the PDE3 inhibitor enoximone substantially reduces established Th2-driven allergic airway inflammation in an HDM-driven asthma mouse model.

Milrinone, a PDE3 inhibitor with a short $t^{1} / 2$, showed an antiinflammatory effect. To confirm our enoximone data, another clinically available PDE3 inhibitor, milrinone, was investigated. Milrinone is a 5-fold more potent PDE3 inhibitor than enoximone (IC50 1.2 and $5.9 \mu \mathrm{mol} / 1$, respectively) (57). It has a shorter $\mathrm{t}^{1 / 2}$ 
A

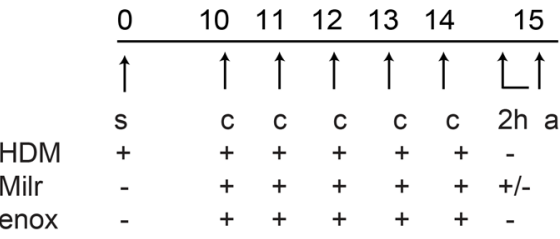

Eosinophils

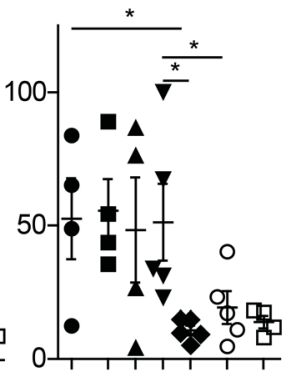

Macrophages

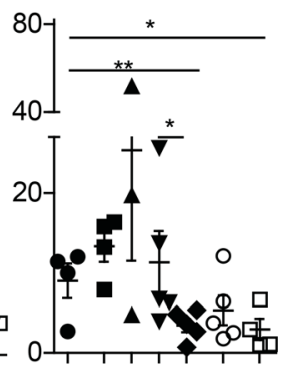

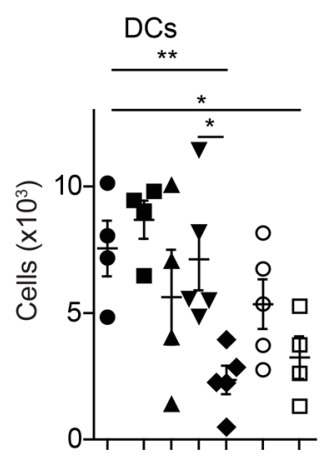

T-cells

Neutrophils
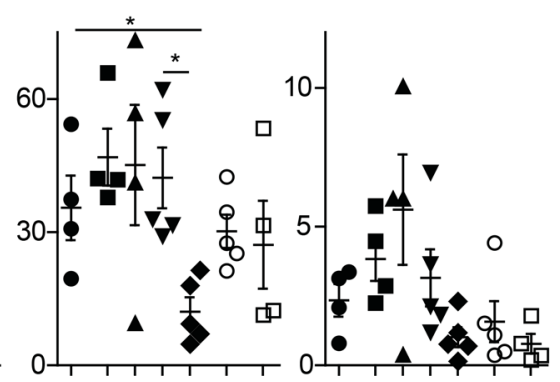

- diluent

- $0.01 \mu \mathrm{g}$ milr

- $0.1 \mu \mathrm{g}$ milr

v $1 \mu \mathrm{g}$ milr

- $10 \mu \mathrm{g}$ milr

- $1 \mu \mathrm{g}$ milr $2 \mathrm{~h}$ before section

ㅁ $25 \mu \mathrm{g}$ enox
Figure 6. PDE3 inhibitor half-life is important for its antiinflammatory effect. (A) Mice were sensitized (s) with house dust mite (HDM) on day 0 and then treated intratracheally with 0.01 , $0.1,1$, and $10 \mu \mathrm{g}$ milrinone (milr) or $25 \mu \mathrm{g}$ enoximone (enox) admixed with house dust mite (HDM). Analyses (a) were performed 1 day after the last challenge (c). The experiment was set up in such a way that the mice that received $1 \mu \mathrm{g}$ milrinone were divided into 2 groups: one that received milrinone on a regular basis, every day, and the last dose 24 hours before the mice were killed; and one that received the last dose of $1 \mu \mathrm{g}$ milrinone 2 hours before the mice were killed. Days after sensitization are indicated at the top. (B) Quantification of flow cytometric analyses of bronchoalveolar lavage (BAL) cells. Kruskal-Wallis test for multiple comparisons was used, followed by Mann-Whitney $U$ test. Data represent 2 separate experiments $(n=$ 4-5 animals per group) and are shown as the mean \pm SEM. ${ }^{*} P<0.05,{ }^{* *} P<0.01$.

than enoximone ( $<2$ hours vs. 7 hours, respectively). We performed a dose-response and timing variation study (Figure 6A) and observed that treatment with $10 \mu \mathrm{g}$ milrinone intratracheally (i.t.) is as potent as $25 \mu \mathrm{g}$ enoximone i.t. in reducing eosinophilic airway inflammation when given during challenge (Figure $6 \mathrm{~B}$ ). In addition, one group received $1 \mu \mathrm{g}$ milrinone 2 hours before sacrificing (Figure 6A). In this group, a reduction was observed in eosinophilic airway inflammation (Figure 6B).

From these experiments, we concluded that targeting PDE3 with optimal doses and timing, milrinone also prevents HDM-driven allergic airway inflammation.

$P D E 3$ inhibition and the expression of CD11b. Given the fast antiallergic response, we investigated whether PDE3 effects on integrin might be associated in allergic airway inflammation. Mouse and human eosinophils express CD11b, an integrin that is crucial for immune cell extravasation (60). Elevated levels of CD11b in neutrophils and eosinophils were seen in affected lung tissue when compared with blood levels (61). Segmental lung antigen challenge upregulates and activates eosinophil integrins in blood and airways of asthmatics (62). From studies in the 1990s it is known that PDE4 inhibition and theophylline can rapidly reduce the expression of CD11b in neutrophils and eosinophils $(63,64)$. BAL eosinophils and neutrophils showed no differences in $\mathrm{CD} 11 \mathrm{~b}$ phenotype when they were obtained from mice lacking PDE3A or PDE3B or WT (Figure 7, A and B). BAL alveolar macrophages expressed lower levels of CD11b when they were obtained from PBS- or HDM-treated mice lacking PDE3A or PDE3B when compared with PBS- or HDM-treated WT mice (Figure 7C). In vitro, $10 \mu \mathrm{M}$ enoximone-treated BAL eosinophils induced by IL-33 treatment (65) showed significantly lower CD11b expression when compared with diluent-treated BAL eosinophils (Figure 7D).

Peripheral blood mononuclear cells (PBMCs) obtained from buffy coats were pretreated with either diluent or enoximone and activated with platelet activation factor (PAF), $N$-formylmethionyl-leucyl-phenylalanine (fMLP), or diluent. PAF and fMLP induced the expression of CD11b in eosinophils (Figure $7 \mathrm{E})$. Lower CD11b expression was observed in ex vivo samples pretreated with enoximone and stimulated with PAF or fMLP (Figure $7, \mathrm{~F}$ and G) when compared with diluent $(n=6)$. CD11b mean fluorescence 
A

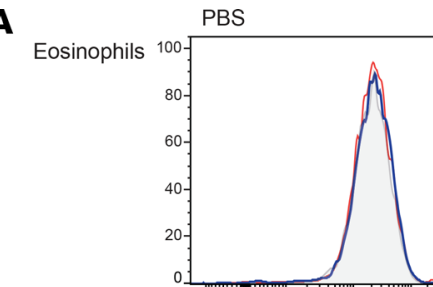

B Neutrophils

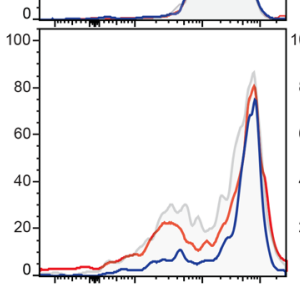

C Alveolar Macrophages 80

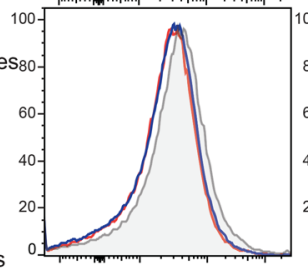

CD 11b

D

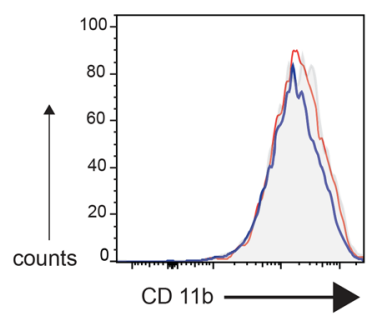

HDM

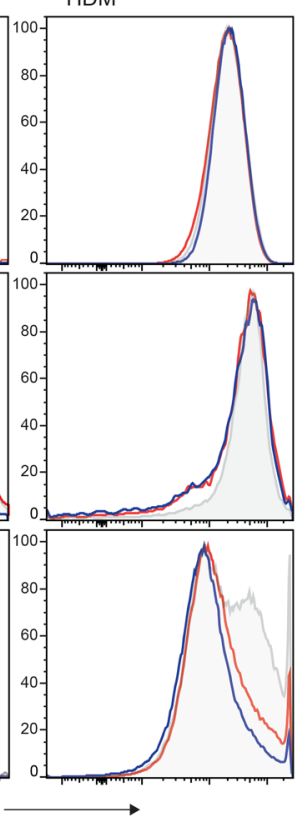

PDE3A -/-

PDE3B -

WT

E

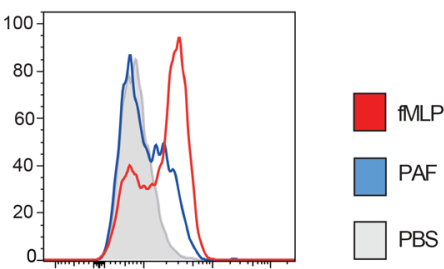

$\mathbf{F}$

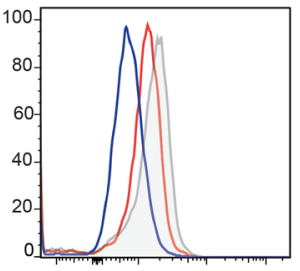

G

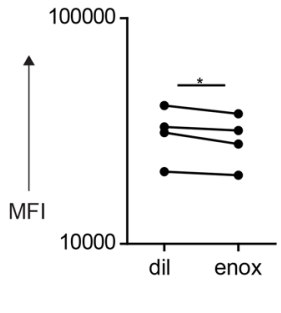

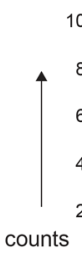

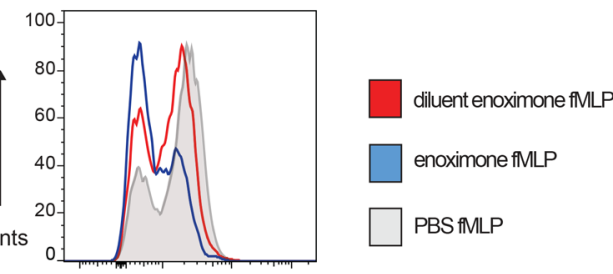

H

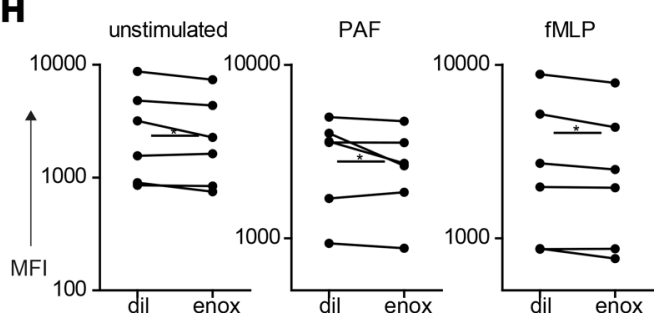

Figure 7. PDE3 activity influences the CD11b expression in eosinophils, neutrophils, and alveolar macrophages. Bronchoalveolar lavage (BAL) cells expressing CD11b obtained from PBS-treated $(n=3)$ or house dust mite-treated (HDM-treated) $(n=6-8) P D E 3 A^{-1-}$, PDE3B $B^{-1-}$, or WT mice. (A) Eosinophils, (B) neutrophils, and (C) alveolar macrophages. (D) In vitro treatment of IL-33-induced BAL cells with the PDE3 inhibitor enoximone (10 $\mu \mathrm{M})$ reduced the expression level mean fluorescence intensity (MFI) of CD11b on eosinophils in mice $(n=4)$. (E) Eosinophils stimulated with platelet activation factor (PAF) or $N$-formylmethionyl-leucyl-phenylalanine (fMLP) were activated and CD11b was induced. In vitro therapy with the PDE3 inhibitor enoximone reduced the expression level of CD11b induced by PAF (F) or fMLP (C). Summary graph compares MFIs from the samples and treatments described above (H). $n=6$ different donors. Data represent 6 separate experiments and are shown as the mean \pm SEM. ${ }^{*} P<0.05$ by paired $t$ test.

intensity (MFI) reduction due to enoximone compared with diluent control treatment was seen in unstimulated, fMLP-, or PAF-stimulated samples (summarized in Figure 7H). These findings imply that decreasing $\mathrm{CD} 11 \mathrm{~b}$ expression is one of the antiinflammatory targeting mechanisms of enoximone with similar characteristics to PDE4 inhibitors.

\section{Discussion}

In our study, we provide evidence that PDE3 plays a pathophysiological role in allergic airway inflammation. In particular, we demonstrated in a physiologically relevant model that HDM-driven allergic inflammation is reduced by targeting PDE3, employing PDE3A- or PDE3B-knockout mice, or by pharmacological inhibition. This reduction was observed when pharmacological intervention was given orally, or topically by means of admixing enoximone with HDM solution followed by intratracheal administration. Hereby, enoximone was also effective when administered to mice with established disease. This potentially novel antiinflammatory observation indicates that besides targeting PDE4 to reduce allergic airway inflammation $(18,66)$, targeting the related enzyme PDE3 also substantially reduces allergic airway inflammation.

The BAL fluid of both $P D E 3 A^{-/-}$and $P D E 3 B^{--}$mice consequently contained significantly lower numbers of inflammatory cells, including eosinophils, as well as less cytokines, when compared with the WT controls. T cell functionality was also affected, as demonstrated by a reduced ability of HDM-restimulated MLN cells to produce and secrete inflammatory cytokines. An important aspect is that the endothelial 
barrier function, which is severely hampered in WT mice following treatment with HDM, was preserved in $P D E 3 A^{-1-}$ or $P D E 3 B^{-1-}$ mice. We observed the mechanisms, but the molecular delineation into the mode of action of PDE3 isoforms in allergic airways disease remains to be clarified.

Inhibition of PDE3 and elevation of cAMP improved epithelial and endothelial barrier function and reduced smooth muscle cell proliferation, which represent important therapeutic effects in the context of asthma treatment (5). Both PDE3 and PDE4 play a key role in regulating cAMP-induced signalling. Levels of intracellular cAMP are important for the type of immune response and affect Th1 and Th2 responses, whereby increased levels of cAMP were found to cause bronchodilation (67). Genome-wide studies in asthma identified an association with a PDE4D polymorphism that is linked to hyperactive PDE4. This polymorphism causes low intracellular levels of cAMP in smooth muscle cells, which is associated with decreased forced exhaled volume in 1 second (FEV1) and bronchial hyperreactivity $(11,14,68)$.

The side effects of treatment with PDE4 inhibitors may be quite severe, physically as well as mentally; even suicides have been reported $(24,69)$. PDE4 inhibitors are rarely prescribed nowadays, owing to these side effects. On the other hand, clinical observations indicate immediate bronchodilation in asthma patients $(8,36,70)$ and in status asthmaticus patients when treated with the PDE3 inhibitor enoximone (32). We would like to underline that the dosage of PDE3 inhibitor enoximone used in early studies that resulted in cardiovascular mortality was very high, 10- to 100-fold higher (up to 2,400 mg) than the dosage used in our case report study (ref. 32 and J. Beute unpublished data). Long-term use of high-dose PDE3 inhibitors is not suitable for heart failure patients (71). PDE3 inhibitor therapy is currently only used in heart failure patients to bridge the period to cardiac transplant and in the ICU to prevent organ failure.

This study shows that a low dose of a not very potent (IC50 5.9 $\mu \mathrm{M})$ PDE3 inhibitor is able to counteract allergic reactions, thereby avoiding severe consequences that may result from potent PDE4 inhibitors or high doses of PDE3 inhibitor. Our model is suitable to study acute allergic inflammation. Studies are underway to investigate the role of PDE3 in airway hyperresponsiveness in a chronic HDM-driven asthma model (A. KleinJan, manuscripts in preparation). The importance of drug $t^{1} / 2$ is illustrated by the results of the comparison between milrinone ( $\mathrm{t}^{1 / 2}<2$ hours) and enoximone ( $\mathrm{t}^{1 / 2}=7$ hours). The $\mathrm{t}^{1 / 2}$ is an important feature of effectiveness in allergic airway inflammation (Figure 6B), but at the same time it is not directly proportional to the effective duration of the drug action. The difference might spring from the metabolite of enoximone being bioactive versus the inactive metabolite of milrinone (72). Earlier studies showed no antiallergic properties; however, the time in between drug administration moments was 24 hours and substantially longer than its $\mathrm{t}^{1} / 2$, and the effect may have waned during incubation. Milrinone may be as effective as enoximone, showing an effect when given in a low dose 2 hours before sampling the mice, but it has to be kept in mind that the $t^{1 / 2}$ of milrinone in healthy subjects is probably less than 2 hours. This is a good feature for an intravenously administered drug (milrinone and enoximone presently are administered in an ICU setting in the treatment of circulatory failure), but not for an oral drug that requires limited administration.

Our mouse data support the clinical observation of the beneficial use of enoximone in the treatment of allergic asthma and show an antiinflammatory effect. The exact mechanism underlying the antiinflammatory effects of enoximone have not yet been elucidated. PDE4 inhibition has a direct effect on the expression of $\mathrm{CD} 11 \mathrm{~b}$ on eosinophils; this is also seen when applying enoximone. Evidence has shown that $\mathrm{CD} 11 \mathrm{~b}$ expression is also reduced by PDE3 mutants and by PDE3 inhibition as a stand-alone agent. When PBMCs were treated with enoximone, the cells could not be activated by PAF or fMLP. There is no difference in the expression level of CD11b on eosinophils in either blood or in induced sputum between healthy controls and asthmatic patients. Although CD11b levels on eosinophils were higher in sputum than in blood, indicating that $\mathrm{CD} 11 \mathrm{~b}$ expression is location dependent and is the highest at the site of inflammation (61), analysis of BAL eosinophils from enoximone- or diluent-treated HDM-challenged mice did not show any differences in CD11b expression, which is in line with human data from in 't Veen et al. (61). They also found the highest CD11b expression in the alveolar compartment, irrespective of having asthma or being healthy (61). A reduction in CD11b prevented extravasation of the CD11b-expressing cells, keeping these cells in the circulation and preventing them from injuring the diseased organ. It has been established that eosinophils can be seen in the pulmonary lymph nodes in asthmatic mice (73). Therapeutic $\mathrm{CD} 11 \mathrm{~b}$ reduction enables the eosinophils to disappear via the lymphatic system or via cough and swallow and prevent extravasation from the circulation. The rapid reduction in CD11b expression in neutrophils and eosinophils due to PDE3 inhibition might be an explanation for why inflammatory cells rapidly disappear when the airways were treated with the PDE3 inhibitors. 
The antiinflammatory effects of enoximone have been established in other studies and are illustrated by reduced serum TNF- $\alpha$ levels during PDE3 inhibition, compared with dobutamine-treated septic patients (38). In alveolar epithelial cells, LPS-induced biosynthesis of proinflammatory cytokines is regulated by cAMP and tightly controlled by PDEs, and can be reduced by PDE inhibitors (74). Reduction in eosinophilic inflammation resulted in reduced exposure to peroxidase and peroxide and reactive oxygen species $(75,76)$. When endothelial cells were exposed to peroxide or other active oxides, permeability of endothelial cells increased, leading to leakage $(77,78)$.

We showed reduced endothelial albumin leakage, as measured by lower concentrations of albumin in BAL fluid or tissue in mice lacking PDE3, or as measured in WT mice treated with a PDE3 inhibitor. We decided to measure the albumin content directly in BAL fluid and not via the indirect method of Evans blue dye $(52,56)$. By measuring albumin in lavage or in tissue, we could clearly see a close correlation between inflammation and albumin concentration. Experimental lung edema and clinical lung edema can evidently be attenuated by selective PDE3 inhibition (44) and/or PDE4 inhibition (39, 44, 78-80).

Enoximone has the advantage that a low dose is already biologically active and has been in clinical use for more than 20 years. Theophylline relaxes human airway smooth muscle cells by inhibiting PDE3 (81). In this context it is of note that theophylline has a nonselective PDE inhibitory activity and only a modest degree of bronchodilatory activity, including antiinflammatory and immunomodulatory activity (81). Using low doses of clinically available PDE3 inhibitory drugs such as enoximone or milrinone, it is possible to bypass the serious side effects that were often seen when asthma patients were treated with the very potent PDE4 inhibitors.

In conclusion: (a) we demonstrated the presence of PDE3 protein and mRNA in human and murine airway tissues, (b) we proved that PDE3 inhibition is an important therapeutic target in the context of allergic airway inflammation, and (c) we concluded that PDE3A or PDE3B deficiency or the inhibition of PDE3 may alleviate the symptoms of allergic airway inflammation. PDE3 inhibitors including enoximone and milrinone are already on the market and in off-label use for other indications, such as pulmonary artery hypertension (PAH) in children (in the UK). Because our study strongly supports the conclusion that targeting PDE3 in allergic airway inflammation may be a novel effective treatment strategy, further research is essential and desirable.

\section{Methods}

Patients for human bronchial biopsies. Patients that met the criteria for asthma, were nonsmoking mild asthmatics, with an FEV1 greater than $60 \%$ predicted (or more than 1.5 liters because of safety aspects), greater than $10 \%$ improvement of FEV1 after maximal bronchodilation and/or increased bronchial hyperresponsiveness (i.e., PC20 methacholine $<8 \mathrm{mg} / \mathrm{ml}$ ), in a stable clinical condition, and sensitized for at least HDM (skin prick test) were enrolled in the study. Healthy controls showed no signs of sensitization and were not hyperreactive.

Animals. $P D E 3 A^{-/-}$and $P D E 3 B^{-1-}$ C57BL/6 mice were previously described $(82,83)$ and showed no abnormalities regarding $\mathrm{T}$ cell development (data not shown). WT C57BL/6 mice were purchased from Envigo. Animals were kept under specific pathogen-free conditions, provided with water and food ad libitum, and were used at the age of 6-12 weeks.

HDM allergic airway inflammation model. To induce airway inflammation, mice were anaesthetized with isofluorane and treated i.t. with $10 \mu \mathrm{g}$ (or as indicated) HDM (Greer Laboratories) allergen extract in 50 $\mu 1$ PBS on day 0 or using PBS only (84). Ten days later, anesthetized mice were challenged with $10 \mu \mathrm{g}$ or $0 \mu \mathrm{g}$ HDM in $50 \mu \mathrm{l}$ PBS intranasally (i.n.) for 5 consecutive days. Mice were sacrificed 24 hours after the last challenge and BAL was performed by flushing the lungs 3 times with $1 \mathrm{ml}$ PBS containing ethylenediaminetetraacetic acid (EDTA, Sigma-Aldrich) (Figure 2A).

Route of treatment, oral and intratracheal doses. Measurements were performed 24 hours after the last challenge.

Optimal dose of $25 \mu \mathrm{g}$ enoximone versus diluent (Figure 5) was administered with $5 \mu \mathrm{g}$ HDM solution and used for intratracheal treatment, or diluent $(10 \%$ ethanol $+40 \%$ glycerol $+50 \%$ Milli-Q water, $\mathrm{pH}$ 12) was administered with $5 \mu \mathrm{g}$ HDM solution. Controls were treated with $25 \mu \mathrm{g}$ enoximone administered with PBS or diluent administered with PBS. Mice underwent enoximone treatment only during challenge.

Treatment strategy 2: established HDM allergy model. C57BL/6 mice were sensitized with $10 \mu \mathrm{g}$ HDM on day 0 and challenged with $5 \mu \mathrm{g}$ HDM for 5 days on days 10-14. Subsequently, the mice were treated with $5 \mu \mathrm{g}$ HDM admixed with $25 \mu \mathrm{g}$ enoximone or diluent for 5 days on days $15-19$. The controls received only PBS (diluent). Twenty-four hours after the last challenge, all animals were sacrificed and sampled. 
Immunohistochemical staining. Stainings were performed in a half-automatic stainer (Sequenza). Acetone-fixed slides were washed with PBS and incubated and blocked in diluted normal goat serum or normal rabbit serum (CLB). Sections were stained with mouse anti-human PDE3A (clone 2D7, Abnova), mouse anti-human PDE3B (clone F-9, Santa Cruz Biotechnology), or rabbit anti-human PDE4 (Fabgennix, cata$\log$ PD4-101AP). The primary antibody was detected using goat anti-mouse long-chain biotin-streptavidin conjugated to alkaline phosphatase (BioGenix), goat anti-rabbit conjugated to alkaline phosphatase (Sigma-Aldrich), or goat anti-PE conjugated to alkaline phosphatase (Rockland, 600-105-387) and rabbit antigoat conjugated to alkaline phosphatase. After rinsing, slides were incubated with New Fuchsin substrate (Sigma-Aldrich). Some slides were stained with goat anti-albumin horseradish peroxidase (HRP) (Bethyl Laboratories, A90-134P) and incubated with Nova Red substrate (Vector). Finally, the sections were counterstained with Gills triple-strength hematoxylin (Sigma-Aldrich) and mounted in VectaMount (Vector). Eosinophils were stained with antibodies against Siglec F (BD Biosciences, 552126) to identify eosinophilic airway inflammation.

Albumin quantification in lung mucosal sections. Albumin quantification was done by taking a representative image from each section and assigning it an ID. These images were then ranked in a blinded fashion (EPK and AKJ) from most to least stained in terms of leakage either peribronchially or perivascularly. Once arranged, the IDs were used to relate which image belonged to which animal. This resulted in an arbitrary rank score to quantify the albumin leakage (Figure 3, $\mathrm{K}$ and $\mathrm{L}$ ).

Analysis of PDE expression. RNA was isolated from patient lung biopsies and mouse whole tissue using a Total RNA Purification Kit (Sigma-Aldrich). Purity of the extracted RNA was verified using a NanoDrop 2000 Spectrophotometer (Thermo Fisher Scientific). From the RNA, cDNA was reverse transcribed using a RevertAid First-Strand cDNA Synthesis Kit (Thermo Fisher Scientific). qPCR primers (for detailed description of primer sequences see Supplemental Tables 1 and 2) specific for all PDE3 and -4 isoforms were designed, using a universal probe library (Roche Diagnostics), and checked for efficiency. Using SYBR Select Master Mix (Applied Biosystems), the cDNA was analyzed via qPCR, using a 7300 Real-Time PCR System (Applied Biosystems). Resulting data were normalized to relative expression of household genes ( $\beta$-actin in human and hypoxanthine-guanine phosphoribosyl transferase [HPRT] in mouse). Resulting data were further analyzed using the comparative $\mathrm{Ct}\left(2^{-\Delta \Delta \mathrm{Ct}}\right)$ method (85).

Flow cytometric analysis. BAL, lung cells, and MLN cells were collected for cellular differentiation by flow cytometry as previously described (84). Eosinophils were identified as cells within the granulocyte gate and positive for Siglec F. T cells were identified as cells in the lymphocyte gate and positive for CD3. DCs were identified as cells in the lymphocyte gate and positive for CD11c and MHCII. In some experiments, a fraction of the isolated cells was stimulated with ionomycin (Sigma-Aldrich), phorbol-12-myristate-13-acetate (PMA, Sigma-Aldrich), and GolgiPlug (BD Biosciences) at $37^{\circ} \mathrm{C}$ for 4 hours. Then, cells were stained for CD3, CD4, and intracellularly for IL-4, IL-5, IL-13, IL-17, and IFN- $\gamma$, after fixation with $2 \%$ paraformaldehyde and permeabilization using a saponin-containing buffer. Fixable Aqua Live/Dead for 405 nm (Invitrogen, Molecular Probes) was used to distinguish between live and dead cells (84). Cells were analyzed using an LSRII flow cytometer (BD Biosciences) and FlowJo software (Tree Star Inc.).

PDE inhibition of eosinophils. PBMCs were isolated from buffy coats of healthy blood donors $(n=6)$ by lysing the red blood cells with lysis buffer $\left(\mathrm{NH}_{4} \mathrm{Cl}\right)$ and washed with $\mathrm{RPMI}$ twice. Then, the cells were incubated with enoximone, rolipram diluent, and PBS for 30 minutes at $37^{\circ} \mathrm{C}$, and next stimulated with PAF (Sigma-Aldrich), fMLP (Sigma-Aldrich), or diluent for 1 hour and washed and stained with Siglec $8^{\mathrm{APC}}$ (Biolegend, 7C9) for eosinophils and markers for non-eosinophils, CD15 ${ }^{\text {PE-CF594 }}$ (BD Biosciences, W6D3), CD14 ${ }^{\mathrm{EF} 450}$ (eBioscience, 61D3), and CD3 $3^{\mathrm{AF} 700}$ (eBioscience, UCHT1). DAPI or Aqua Live/Dead was used to distinguish between live and dead cells. Based on forward scatter (FSC) and side scatter (SSC) to identify the granulocyte population, eosinophils were selected and CD11b (ICRF44) expression was evaluated on live eosinophils. Treatment of cells was performed with $1 \mu \mathrm{M}$ PAF and $10 \mu \mathrm{M}$ fMLP and diluent $(10 \%$ ethanol $+40 \%$ glycerol $+50 \%$ Milli-Q water), $25 \mu \mathrm{g} / \mathrm{ml}$ enoximone.

Statistics. Reported values are shown as the mean \pm SEM. Statistical analyses were performed with SPSS (SPSS Inc.) using Kruskal-Wallis 1-way ANOVA followed by Mann-Whitney $U$ test. Mann-Whitney $U$ test was only performed if the 1-way ANOVA test pointed to significance and the Sign $t$ test for paired samples. Resulting $P$ values less than $0.05\left(^{*}\right)$ and $0.01\left(^{* *}\right)$ are indicated and considered significant. Tests that did not reach significance $(P>0.05)$ are not indicated. 
Study approval. All participants provided informed written consent, which was approved by the medical ethics committee of the Erasmus Medical Center, Rotterdam, The Netherlands. Data from these patients were previously described $(86,87)$; detailed descriptions of the characterizations of the bronchial mucosa biopsies obtained from asthmatics showed more eosinophils than those obtained from healthy controls - see Supplemental Figure 1E. Peripheral blood cells were isolated from buffy coats of blood donors (Sanquin Bloedvoorziening, NVT nr. 0014.03, Rotterdam, The Netherlands). All animal experiments were approved by the Erasmus MC Animal Ethics Committee.

\section{Author contributions}

JB and AK contributed to study design and wrote and edited the manuscript. ML, EPK, KG, HN, MJWB, MVN, AK, and BNL contributed to performing the studies and obtaining the samples analyzed in this study. SH, VCM, GJB, LB, BNL, and RWH were involved in reviewing and shaping the manuscript. All approved the final version before submission.

\section{Acknowledgments}

This study is supported by Stichting Astma Bestrijding. Vincent Manganiello sadly died prior to completion of the manuscript. Vincent Manganiello and Steven Hockman were supported by the intramural research program NIH/NHLBI. Joel Moss, a long-time NHLBI colleague of Vincent Manganiello, assumed responsibility for its content.

Address correspondence to: Alex KleinJan, Department of Pulmonary Medicine, Erasmus MC, 's-Gravendijkwal 230, 3015 CE, Rotterdam, The Netherlands. Phone: 31.10.704.3698; Email: a.kleinjan@erasmusmc.nl.

1. Barnes PJ. Immunology of asthma and chronic obstructive pulmonary disease. Nat Rev Immunol. 2008;8(3):183-192.

2. Hekking PP, Wener RR, Amelink M, Zwinderman AH, Bouvy ML, Bel EH. The prevalence of severe refractory asthma. J Allergy Clin Immunol. 2015;135(4):896-902.

3. Asthma Death Rate Per 100,000 Age Standardize. World Health rankings. http://www.worldlifeexpectancy.com/cause-ofdeath/asthma/by-country/. Accessed December 20, 2017.

4. Souness JE, Aldous D, Sargent C. Immunosuppressive and anti-inflammatory effects of cyclic AMP phosphodiesterase (PDE) type 4 inhibitors. Immunopharmacology. 2000;47(2-3):127-162.

5. Beavo JA. Cyclic nucleotide phosphodiesterases: functional implications of multiple isoforms. Physiol Rev. 1995;75(4):725-748.

6. Blease K, Burke-Gaffney A, Hellewell PG. Modulation of cell adhesion molecule expression and function on human lung microvascular endothelial cells by inhibition of phosphodiesterases 3 and 4. Br J Pharmacol. 1998;124(1):229-237.

7. Boswell-Smith V, Spina D, Oxford AW, Comer MB, Seeds EA, Page CP. The pharmacology of two novel long-acting phosphodiesterase 3/4 inhibitors, RPL554 [9,10-dimethoxy-2(2,4,6-trimethylphenylimino)-3-(n-carbamoyl-2-aminoethyl)-3,4,6,7-tetrahydro-2H-pyrimido[6,1-a]isoquinolin-4-one] and RPL565 [6,7-dihydro-2-(2,6-diisopropylphenoxy)-9,10-dimethoxy-4H-pyrimido[6,1-a]isoquinolin-4-one]. J Pharmacol Exp Ther. 2006;318(2):840-848.

8. Myou S, et al. Bronchodilator effect of inhaled olprinone, a phosphodiesterase 3 inhibitor, in asthmatic patients. Am J Respir Crit Care Med. 1999;160(3):817-820.

9. Wright LC, Seybold J, Robichaud A, Adcock IM, Barnes PJ. Phosphodiesterase expression in human epithelial cells. Am J Physiol. 1998;275(4 Pt 1):L694-L700.

10. KleinJan A. Airway inflammation in asthma: key players beyond the Th2 pathway. Curr Opin Pulm Med. 2016;22(1):46-52.

11. Himes BE, et al. Genome-wide association analysis identifies PDE4D as an asthma-susceptibility gene. Am J Hum Genet. 2009;84(5):581-593.

12. Obeidat $\mathrm{M}$, et al. A comprehensive evaluation of potential lung function associated genes in the SpiroMeta general population sample. PLoS One. 2011;6(5):e19382.

13. Portelli M, Sayers I. Genetic basis for personalized medicine in asthma. Expert Rev Respir Med. 2012;6(2):223-236

14. Trian T, et al. $\beta 2$-Agonist induced cAMP is decreased in asthmatic airway smooth muscle due to increased PDE4D. PLoS One. 2011;6(5):e20000.

15. Jin SL, et al. Phosphodiesterase 4B is essential for $\mathrm{T}(\mathrm{H}) 2$-cell function and development of airway hyperresponsiveness in allergic asthma. J Allergy Clin Immunol. 2010;126(6):1252-1259.e12.

16. Chapman RW, et al. Effect of inhaled roflumilast on the prevention and resolution of allergen-induced late phase airflow obstruction in Brown Norway rats. Eur J Pharmacol. 2007;571(2-3):215-221.

17. Hansen G, Jin S, Umetsu DT, Conti M. Absence of muscarinic cholinergic airway responses in mice deficient in the cyclic nucleotide phosphodiesterase PDE4D. Proc Natl Acad Sci USA. 2000;97(12):6751-6756.

18. Kanehiro A, et al. Inhibition of phosphodiesterase 4 attenuates airway hyperresponsiveness and airway inflammation in a model of secondary allergen challenge. Am J Respir Crit Care Med. 2001;163(1):173-184.

19. Meng JF, Rosenwasser LJ. Unraveling the genetic basis of asthma and allergic diseases. Allergy Asthma Immunol Res. 2010;2(4):215-227.

20. Leeman M, Lejeune P, Melot C, Naeije R. Reduction in pulmonary hypertension and in airway resistances by enoximone 
(MDL 17,043) in decompensated COPD. Chest. 1987;91(5):662-666.

21. Franciosi LG, et al. Efficacy and safety of RPL554, a dual PDE3 and PDE4 inhibitor, in healthy volunteers and in patients with asthma or chronic obstructive pulmonary disease: findings from four clinical trials. Lancet Respir Med. 2013;1(9):714-727.

22. Barnes PJ. Therapeutic approaches to asthma-chronic obstructive pulmonary disease overlap syndromes. J Allergy Clin Immunol. 2015;136(3):531-545.

23. Pérez-Torres S, Miró X, Palacios JM, Cortés R, Puigdoménech P, Mengod G. Phosphodiesterase type 4 isozymes expression in human brain examined by in situ hybridization histochemistry and $\left[{ }^{3} \mathrm{H}\right]$ rolipram binding autoradiography. Comparison with monkey and rat brain. J Chem Neuroanat. 2000;20(3-4):349-374.

24. Banner KH, Press NJ. Dual PDE3/4 inhibitors as therapeutic agents for chronic obstructive pulmonary disease. Br J Pharmacol. 2009;157(6):892-906.

25. Rabe KF. Update on roflumilast, a phosphodiesterase 4 inhibitor for the treatment of chronic obstructive pulmonary disease. $B r$ J Pharmacol. 2011;163(1):53-67.

26. BinMahfouz H, Borthakur B, Yan D, George T, Giembycz MA, Newton R. Superiority of combined phosphodiesterase PDE3/ PDE4 inhibition over PDE4 inhibition alone on glucocorticoid- and long-acting $\beta 2$-adrenoceptor agonist-induced gene expression in human airway epithelial cells. Mol Pharmacol. 2015;87(1):64-76.

27. Moodley T, et al. Phosphodiesterase 4 inhibitors augment the ability of formoterol to enhance glucocorticoid-dependent gene transcription in human airway epithelial cells: a novel mechanism for the clinical efficacy of roflumilast in severe chronic obstructive pulmonary disease. Mol Pharmacol. 2013;83(4):894-906.

28. Maurice DH, Ke H, Ahmad F, Wang Y, Chung J, Manganiello VC. Advances in targeting cyclic nucleotide phosphodiesterases. Nat Rev Drug Discov. 2014;13(4):290-314.

29. Kobayashi K, Tsubosaka Y, Hori M, Narumiya S, Ozaki H, Murata T. Prostaglandin D2-DP signaling promotes endothelial barrier function via the cAMP/PKA/Tiam1/Rac1 pathway. Arterioscler Thromb Vasc Biol. 2013;33(3):565-571.

30. Boswell-Smith V, Cazzola M, Page CP. Are phosphodiesterase 4 inhibitors just more theophylline? J Allergy Clin Immunol. 2006;117(6):1237-1243

31. Planquois JM, Mottin G, Artola M, Lagente V, Payne A, Dahl S. Effects of phosphodiesterase inhibitors and salbutamol on microvascular leakage in guinea-pig trachea. Eur J Pharmacol. 1998;344(1):59-66.

32. Beute J. Emergency treatment of status asthmaticus with enoximone. Br J Anaesth. 2014;112(6):1105-1108.

33. Banner KH, Marchini F, Buschi A, Moriggi E, Semeraro C, Page CP. The effect of selective phosphodiesterase inhibitors in comparison with other anti-asthma drugs on allergen-induced eosinophilia in guinea-pig airways. Pulm Pharmacol. 1995;8(1):37-42.

34. Lagente V, Pruniaux MP, Junien JL, Moodley I. Modulation of cytokine-induced eosinophil infiltration by phosphodiesterase inhibitors. Am J Respir Crit Care Med. 1995;151(6):1720-1724.

35. Foissier L, Lonchampt M, Cogé F, Canet E. In vitro down-regulation of antigen-induced IL-5 gene expression and protein production by cAMP-specific phosphodiesterase type 4 inhibitor. J Pharmacol Exp Ther. 1996;278(3):1484-1490

36. Howell RE, Jenkins LP, Fielding LE, Grimes D. Inhibition of antigen-induced pulmonary eosinophilia and neutrophilia by selective inhibitors of phosphodiesterase types 3 or 4 in Brown Norway rats. Pulm Pharmacol. 1995;8(2-3):83-89.

37. Hayashida N, et al. Inhibitory effect of milrinone on cytokine production after cardiopulmonary bypass. Ann Thorac Surg. 1999;68(5):1661-1667.

38. Kern H, Schröder T, Kaulfuss M, Martin M, Kox WJ, Spies CD. Enoximone in contrast to dobutamine improves hepatosplanchnic function in fluid-optimized septic shock patients. Crit Care Med. 2001;29(8):1519-1525.

39. Wang SM. Milrinone in enterovirus 71 brain stem encephalitis. Front Pharmacol. 2016;7:82.

40. Jung WK, et al. Cilostazol is anti-inflammatory in BV2 microglial cells by inactivating nuclear factor-kappaB and inhibiting mitogen-activated protein kinases. Br J Pharmacol. 2010;159(6):1274-1285.

41. Agrawal NK, Maiti R, Dash D, Pandey BL. Cilostazol reduces inflammatory burden and oxidative stress in hypertensive type 2 diabetes mellitus patients. Pharmacol Res. 2007;56(2):118-123.

42. da Motta NA, de Brito FC. Cilostazol exerts antiplatelet and anti-inflammatory effects through AMPK activation and NF-kB inhibition on hypercholesterolemic rats. Fundam Clin Pharmacol. 2016;30(4):327-337.

43. Baek AE, Kanthi Y, Sutton NR, Liao H, Pinsky DJ. Regulation of ecto-apyrase CD39 (ENTPD1) expression by phosphodiesterase III (PDE3). FASEB J. 2013;27(11):4419-4428.

44. Mokra D, Drgova A, Pullmann R, Calkovska A. Selective phosphodiesterase 3 inhibitor olprinone attenuates meconium-induced oxidative lung injury. Pulm Pharmacol Ther. 2012;25(3):216-222.

45. Oishi $\mathrm{H}$, et al. Olprinone and colforsin daropate alleviate septic lung inflammation and apoptosis through CREB-independent activation of the Akt pathway. Am J Physiol Lung Cell Mol Physiol. 2012;303(2):L130-L140.

46. Di Paola R, Mazzon E, Paterniti I, Impellizzeri D, Bramanti P, Cuzzocrea S. Olprinone, a PDE3 inhibitor, modulates the inflammation associated with myocardial ischemia-reperfusion injury in rats. Eur J Pharmacol. 2011;650(2-3):612-620.

47. Esposito E, Mazzon E, Paterniti I, Impellizzeri D, Bramanti P, Cuzzocrea S. Olprinone attenuates the acute inflammatory response and apoptosis after spinal cord trauma in mice. PLoS ONE. 2010;5(9):e12170.

48. Wang Q, et al. Anti-inflammatory profile of levosimendan in cecal ligation-induced septic mice and in lipopolysaccharide-stimulated macrophages. Crit Care Med. 2015;43(11):e508-e520.

49. Nony P, et al. Evaluation of the effect of phosphodiesterase inhibitors on mortality in chronic heart failure patients. A meta-analysis. Eur J Clin Pharmacol. 1994;46(3):191-196.

50. Packer M, et al. Effect of oral milrinone on mortality in severe chronic heart failure. The PROMISE Study Research Group. NEngl J Med. 1991;325(21):1468-1475

51. Metra M, et al. Effects of low-dose oral enoximone administration on mortality, morbidity, and exercise capacity in patients with advanced heart failure: the randomized, double-blind, placebo-controlled, parallel group ESSENTIAL trials. Eur Heart J. 2009;30(24):3015-3026

52. Löser S, et al. Pulmonary ORMDL3 is critical for induction of Alternaria-induced allergic airways disease. J Allergy Clin Immunol. 2017;139(5):1496-1507.e3.

53. Steelant B, et al. Histamine and T helper cytokine driven epithelial barrier dysfunction in allergic rhinitis [published online 
ahead of print October 23, 2017]. J Allergy Clin Immun. https://doi.org/10.1016/j.jaci.2017.08.039.

54. Dunnill MS. The pathology of asthma, with special reference to changes in the bronchial mucosa. J Clin Pathol. 1960;13:27-33.

55. Liu S, Yu C, Yang F, Paganini-Hill A, Fisher MJ. Phosphodiesterase inhibitor modulation of brain microvascular endothelial cell barrier properties. J Neurol Sci. 2012;320(1-2):45-51.

56. Wang HL, Lai TW. Optimization of Evans blue quantitation in limited rat tissue samples. Sci Rep. 2014;4:6588.

57. Bethke T, et al. Phosphodiesterase inhibition by enoximone in preparations from nonfailing and failing human hearts. Arzneimit telforschung. 1992;42(4):437-445.

58. Staeben M, Kleman-Leyer KM, Kopp AL, Westermeyer TA, Lowery RG. Development and validation of a transcreener assay for detection of AMP- and GMP-producing enzymes. Assay Drug Dev Technol. 2010;8(3):344-355.

59. Eschenhagen T. PDE4 in the human heart - major player or little helper? Br J Pharmacol. 2013;169(3):524-527.

60. Johansson MW. Activation states of blood eosinophils in asthma. Clin Exp Allergy. 2014;44(4):482-498.

61. in 't Veen JC, et al. CD11b and L-selectin expression on eosinophils and neutrophils in blood and induced sputum of patients with asthma compared with normal subjects. Clin Exp Allergy. 1998;28(5):606-615.

62. Johansson MW, Kelly EA, Busse WW, Jarjour NN, Mosher DF. Up-regulation and activation of eosinophil integrins in blood and airway after segmental lung antigen challenge. J Immunol. 2008;180(11):7622-7635.

63. Berends C, Dijkhuizen B, de Monchy JG, Dubois AE, Gerritsen J, Kauffman HF. Inhibition of PAF-induced expression of $\mathrm{CD} 11 \mathrm{~b}$ and shedding of L-selectin on human neutrophils and eosinophils by the type IV selective PDE inhibitor, rolipram. Eur Respir J. 1997;10(5):1000-1007.

64. Spoelstra FM, Berends C, Dijkhuizen B, de Monchy JG, Kauffman HF. Effect of theophylline on CD11b and L-selectin expression and density of eosinophils and neutrophils in vitro. Eur Respir J. 1998;12(3):585-591.

65. KleinJan A, et al. The Notch pathway inhibitor SAHM1 abrogates the hallmarks of allergic asthma [published online ahead of print October 27, 2017]. J Allergy Clin Immunol. https://doi.org/10.1016/j.jaci.2017.08.042.

66. Beghè B, Rabe KF, Fabbri LM. Phosphodiesterase-4 inhibitor therapy for lung diseases. Am J Respir Crit Care Med. 2013;188(3):271-278.

67. Torphy TJ. Beta-adrenoceptors, cAMP and airway smooth muscle relaxation: challenges to the dogma. Trends Pharmacol Sci. 1994;15(10):370-374.

68. Lin AH, Shang Y, Mitzner W, Sham JS, Tang WY. Aberrant DNA methylation of phosphodiesterase [corrected] 4D Alters airway smooth muscle cell phenotypes. Am J Respir Cell Mol Biol. 2016;54(2):241-249.

69. Rabe KF. Update on roflumilast, a phosphodiesterase 4 inhibitor for the treatment of chronic obstructive pulmonary disease. $B r$ J Pharmacol. 2011;163(1):53-67.

70. Fujimura M, Kamio Y, Myou S, Hashimoto T, Matsuda T. Effect of a phosphodiesterase 3 inhibitor, cilostazol, on bronchial hyperresponsiveness in elderly patients with asthma. Int Arch Allergy Immunol. 1997;114(4):379-384.

71. Ding B, et al. A positive feedback loop of phosphodiesterase 3 (PDE3) and inducible cAMP early repressor (ICER) leads to cardiomyocyte apoptosis. Proc Natl Acad Sci USA. 2005;102(41):14771-14776.

72. Okerholm RA, Chan KY, Lang JF, Thompson GA, Ruberg SJ. Biotransformation and pharmacokinetic overview of enoximone and its sulfoxide metabolite. Am J Cardiol. 1987;60(5):21C-26C.

73. van Rijt LS, Vos N, Hijdra D, de Vries VC, Hoogsteden HC, Lambrecht BN. Airway eosinophils accumulate in the mediastina lymph nodes but lack antigen-presenting potential for naive T cells. J Immunol. 2003;171(7):3372-3378.

74. Haddad JJ, Land SC, Tarnow-Mordi WO, Zembala M, Kowalczyk D, Lauterbach R. Immunopharmacological potential of selective phosphodiesterase inhibition. I. Differential regulation of lipopolysaccharide-mediated proinflammatory cytokine (interleukin-6 and tumor necrosis factor-alpha) biosynthesis in alveolar epithelial cells. J Pharmacol Exp Ther. 2002;300(2):559-566.

75. Wu W, et al. Eosinophils generate brominating oxidants in allergen-induced asthma. J Clin Invest. 2000;105(10):1455-1463.

76. Jacobsen EA, Lee NA, Lee JJ. Re-defining the unique roles for eosinophils in allergic respiratory inflammation. Clin Exp Allergy. 2014;44(9):1119-1136

77. Pearse DB, et al. Effect of cGMP on lung microvascular endothelial barrier dysfunction following hydrogen peroxide. Endothelium. 2003;10(6):309-317.

78. Suttorp N, et al. Hyperpermeability of pulmonary endothelial monolayer: protective role of phosphodiesterase isoenzymes 3 and 4. Lung. 1996;174(3):181-194.

79. Fanelli V, et al. Pulmonary-derived phosphoinositide 3-kinase gamma (PI3K $\gamma$ ) contributes to ventilator-induced lung injury and edema. Intensive Care Med. 2010;36(11):1935-1945.

80. Van der Mey M, et al. Synthesis and structure-activity relationships of cis-tetrahydrophthalazinone/pyridazinone hybrids: a novel series of potent dual PDE3/PDE4 inhibitory agents. J Med Chem. 2003;46(10):2008-2016.

81. Barnes PJ. Theophylline. Am J Respir Crit Care Med. 2013;188(8):901-906.

82. Choi YH, et al. Alterations in regulation of energy homeostasis in cyclic nucleotide phosphodiesterase 3B-null mice. J Clin Invest. 2006;116(12):3240-3251.

83. Masciarelli S, et al. Cyclic nucleotide phosphodiesterase 3A-deficient mice as a model of female infertility. J Clin Invest. 2004;114(2):196-205.

84. KleinJan A, et al. Enforced expression of Gata3 in T cells and group 2 innate lymphoid cells increases susceptibility to allergic airway inflammation in mice. J Immunol. 2014;192(4):1385-1394.

85. Wong ML, Medrano JF. Real-time PCR for mRNA quantitation. BioTechniques. 2005;39(1):75-85.

86. Braunstahl GJ, Fokkens WJ, Overbeek SE, KleinJan A, Hoogsteden HC, Prins JB. Mucosal and systemic inflammatory changes in allergic rhinitis and asthma: a comparison between upper and lower airways. Clin Exp Allergy. 2003;33(5):579-587.

87. van den Toorn LM, Overbeek SE, de Jongste JC, Leman K, Hoogsteden HC, Prins JB. Airway inflammation is present during clinical remission of atopic asthma. Am J Respir Crit Care Med. 2001;164(11):2107-2113. 